\title{
Inquérito vacinal de alunos da graduação em medicina e enfermagem da Faculdade de Medicina de São José do Rio Preto (SP, Brasil) nos anos de 2006 e 2007 e suas possíveis implicações na atuação discente
}

\author{
Vaccines inquiry of enrolled medical and nursing students \\ at School of Medicine of São José do Rio Preto (SP, Brazil), \\ in the years of 2006 and 2007, and the possible involvements \\ at pupil acting
}

\author{
Eliana Márcia Sotello Cabrera ${ }^{1}$ \\ Carolina Elisabete da Silva Merege ${ }^{1}$
}

${ }^{1}$ Faculdade de Medicina de São José do Rio Preto. Av. Brigadeiro Faria Lima 5.416, Bairro São Pedro. 15090-000 São José do Rio Preto SP. escabrera@famerp.br

\begin{abstract}
According to their susceptibility, health workers have higher risk to vaccine-preventable diseases (intramural transmission in hospitals), and can also be a source of infection to others professionals and patients. The aim of this article is to get and describe the vaccination status of the student population at Famerp (São José do Rio Preto, São Paulo, Brazil); to show the importance of keeping a vaccine protocol inquiry and immunization with recommended vaccines for students at Famerp, and others susceptible institutions. The methodology used was a population census of the enrolled medical and nursing students at Famerp, in 2006 and 2007, with application of a closed questionnaire to establish bio-psycho-socio-cultural characteristics of vaccinal relevance. It could be perceived that there isn't a specific immunization program for students at Famerp. We verified that among the 375 interviewed students (59.8\%), the majority (59.7\%) had related to know the possible adverse reactions, and $66.9 \%$ weren't afraid of adverse reactions. Only 69 students (11.0\%) presented the vaccine register spontaneously. None of the students presented the vaccines of the adult or health professional routine. It's imperative to work in health planning and regulation, standardized at Famerp and higher education institutions, to protect the susceptible population.
\end{abstract}

Key words Immunizations program, Healthcare workers, Inquiry of vaccines
Resumo Profissionais da saúde têm risco aumentado para doenças imunopreveníveis (transmissão intra-hospitalar), conforme sua suscetibilidade, e podem ser fonte de infecção a outros profissionais e a pacientes. Este artigo tem como objetivos levantar e descrever o estado vacinal da população dos estudantes da Faculdade de Medicina de São José do Rio Preto; mostrar a necessidade de manutenção de protocolo de inquérito vacinal e imunização, por vacinas recomendadas, do aluno da Famerp e de outras instituições. Utilizou-se o censo populacional dos estudantes de medicina e enfermagem da Famerp matriculados em 2006 e 2007, com aplicação de questionário fechado com caracterização biopsicossociocultural, relevante à vacinação. Não há um programa específico de imunização do corpo discente da Famerp. Pudemos verificar que dos 375 alunos $(59,8 \%)$ entrevistados, a maioria referiu conhecer as possiveis reações adversas (59,7\%) e também não ter medo dessas reações (66,9\%). Apenas 69 alunos (11,0\%) apresentaram espontaneamente a carteira vacinal. Nenhuma das carteiras apresentou-se em dia com as vacinas de rotina do adulto e dos profissionais de saúde. São imperativos planejamento e ação em saúde regular, normatizada na Famerp e em instituições de ensino superior, para proteção da população suscetível.

Palavras-chave Programas de vacinação, Profissionais da saúde, Inquérito epidemiológico 


\section{Introdução}

Os programas de imunização foram se consolidando gradualmente no Brasil, especialmente nos últimos trinta anos. O Programa Nacional de Imunizações (PNI) e o Programa Estadual de Imunizações (PEI) visam alcançar alta cobertura vacinal, com o objetivo final de manutenção de adequado grau de proteção imunológica da população contra as doenças transmissíveis imunopreveníveis ${ }^{1,2}$.

Os profissionais da saúde têm risco aumentado para doenças imunopreveníveis, com possibilidade de transmissão intra-hospitalar, e risco significativo de contraí-las e/ou transmiti-las, conforme sua suscetibilidade ${ }^{3}$.

Para os futuros e atuais profissionais de saúde, objeto deste estudo, é disponibilizada pelo PNI e pelo PEI imunização contra: hepatite B (risco de acidentes perfurocortantes), varicela, tríplice viral (sarampo, caxumba e rubéola), febre amarela (município pertencente à área de risco para febre amarela), dupla adulto (tétano e difteria) e influenza sazonal (disponível anualmente para idosos e populações de risco $)^{4,5}$.

Para a população geral, as vacinas são disponíveis como indicado a seguir: hepatite B para crianças e adolescentes até 19 anos de idade; febre amarela; dupla adulto, disponível para toda a população (ambas com reforço vacinal a cada dez anos); e influenza sazonal, disponível anualmente para idosos ${ }^{4,5}$.

É importante a adesão à realização de vacinação dos profissionais, pois tira os profissionais do estado de suscetíveis e potenciais fontes de infecção a outros profissionais e a pacientes.

$\mathrm{Na}$ Faculdade de Medicina de São José do Rio Preto (Famerp), não há um programa específico de imunização do corpo discente, tanto de medicina quanto de enfermagem. Toda instituição e unidade de saúde devem assegurar que os trabalhadores sejam imunizados e informados das vantagens, assim como dos riscos a que estarão expostos por falta ou recusa em se imunizar.

$\mathrm{O}$ aluno de graduação de medicina ou enfermagem não constitui vínculo empregatício com a instituição de ensino superior (IES), porém há a responsabilidade moral específica como unidade de ensino. Ao analisarmos a grade curricular a ser cumprida, constata-se a presença do aluno em várias oportunidades e por períodos e tempo de permanências diferentes em unidades da rede de saúde. Mostra-se, portanto, importante a realização de inquérito vacinal, que é subsídio para diagnóstico de saúde em relação à imunização do corpo discente para o planejamento de ação de saúde consistente e normatizada na instituição ${ }^{4,6}$.

Aos graduandos do curso de enfermagem, dever-se-ia considerar a vacinação contra a hepatite A, já que o tipo de transmissão (fecal-oral) expõe mais esta categoria discente. Idealmente, ambos os cursos (medicina e enfermagem) deveriam ser submetidos a toda a rotina vacinal antes de contato com os pacientes na rede de serviços de saúde.

Os currículos dos cursos de medicina e enfermagem preveem o aluno inserido na rede de saúde precocemente, havendo atividades tanto em serviços como na comunidade, desde o primeiro ano discente, na Atenção Básica, Secundária e Terciária ${ }^{7}$. Outra prática estabelecida é o exercício de atividades diversas de caráter voluntário voltadas à formação, pesquisa, ensino e/ou extensão em área específica da saúde de interesse do aluno, envolvendo ambos os cursos da IES.

A partir do terceiro ano médico e de enfermagem, o contato dos alunos com pacientes hospitalizados ou em atendimento em emergências e/ou ambulatórios é cada vez mais frequente. O risco biológico fica mais evidente à medida que a frequência ao ambiente hospitalar aumenta.

A suscetibilidade dos alunos às doenças infecciosas imunopreveníveis desde o início dos cursos de saúde e as atividades que envolvem diretamente o paciente aumentam o risco de infecção para ambos. Há que se considerar ainda o risco potencial para os contatos secundários desse aluno suscetível, que não são objeto de estudo deste artigo. Esse risco poderia ser estimado por meio de modelagem matemática, em estudo adequadamente desenhado ${ }^{4}$.

É clara a necessidade de imunização do profissional da área de saúde, segundo a Norma Regulamentadora $\mathrm{n}^{\circ} 32$ (NR-32), que versa sobre a segurança do trabalhador em saúde ${ }^{8}$. A falta de regulamentação nas instituições de ensino, especialmente de nível técnico e superior na área de saúde, pode aumentar a vulnerabilidade da classe discente especificamente às doenças imunopreveníveis como febre amarela, hepatite B, hepatite A, varicela, influenza sazonal, difteria e tétano, sarampo, caxumba e rubéola, expondo essa população e as pessoas que estiverem sob seus cuidados a riscos evitáveis ${ }^{2-4,8}$.

A iniciativa da própria IES pode ser suficiente para garantir que a rotina básica de imunização do profissional de saúde seja garantida ao graduando, com proteção específica primária do corpo discente.

O objetivo geral deste estudo é levantar o estado vacinal da população dos estudantes de 
medicina e enfermagem da Famerp, documentado em carteira vacinal. Os objetivos específicos são: verificar perfil vacinal do aluno e comparar a imunização preconizada aos profissionais da área de saúde; alertar para a necessidade da prevenção de riscos imunopreveníveis no âmbito dos profissionais de saúde em formação.

\section{Material e métodos}

Esta pesquisa foi realizada na Faculdade de Medicina de São José do Rio Preto (SP), 442 quilômetros a noroeste de São Paulo, polo regional

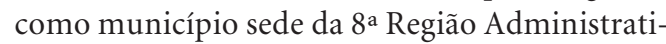
va do Estado de São Paulo, como um estudo ecológico, do tipo censo populacional, dos estudantes de medicina e enfermagem da Famerp, de $1^{\circ}$ agosto de 2006 a 31 de julho de $2007^{9}$.

$\mathrm{O}$ agendamento de aplicação da pesquisa com os representantes de classes de cada ano da graduação foi a primeira oportunidade de solicitação da carteira vacinal. Previamente ou no momento da aplicação do questionário, foi entregue convocação escrita para que a classe discente trouxesse carteira vacinal para xerox.

O terceiro momento foi aviso em sala por aluna de iniciação científica envolvida neste estudo. Nas salas do curso de medicina, a pesquisadora ainda fez outro alerta durante aulas dadas em quatro turmas do curso de medicina (primeiro, segundo, quarto e quinto anos médicos).

Realizou-se cópia xerográfica das carteiras vacinais dos alunos de medicina e enfermagem, após solicitação escrita, solicitação oral, avisos em aulas do Departamento de Epidemiologia e Saúde Coletiva, espontaneamente pelos alunos. Foi aplicado, concomitantemente, questionário fechado individual, por salas de aula. Os alunos presentes e voluntários foram incluídos na pesquisa. Este projeto foi submetido à aprovação do Comitê de Ética em Pesquisa da Faculdade de Medicina de São José do Rio Preto (CEP/Famerp).

\section{Resultados}

O número de alunos pesquisados por meio de questionários ficou distribuído, segundo as turmas dos cursos de graduação na Famerp, conforme a Tabela 1.

Os alunos que responderam aos questionários foram principalmente da medicina $(74,4 \%)$, solteiros $(97,6 \%)$, a maior parte do gênero feminino $(65,5 \%)$.

A escolaridade dos pais e mães, declarada, foi ensino superior completo ou pós-graduação (55,7\% para ambos), seguida por ensino médio completo ( $19,2 \%$ e $18,1 \%$, respectivamente). O estado de origem principal é São Paulo (90,7\%), seguido por Minas Gerais (5,6\%). Outros oito estados foram apontados, porém com frequência máxima de 0,8\% (GO).

Dos alunos da Famerp, 38,4\% moram com amigos da faculdade, $29,1 \%$ sozinhos e $20,3 \%$ com os pais; $93,6 \%$ não têm renda própria. A renda familiar variou entre um e cem salários mínimos (classe modal: $10 \mathrm{SM}$ ); 33,3\% não declararam a renda; $15,4 \%$ declararam renda de dez salários mínimos (SM) e 7,6\% de quatro SM.

Tabela 1. Distribuição por turma da população pesquisada esperada e obtida dos alunos de graduação de medicina e enfermagem da Faculdade de Medicina de São José do Rio Preto (SP), de $1^{\circ}$ de agosto de 2006 a 31 de julho de 2007 .

\begin{tabular}{llcrr}
\hline Turmas 2007 & Curso & Alunos matriculados & Alunos obtidos (n) & Freq (\%) \\
\hline$\left(1^{\circ}\right.$ ano $)$ & Medicina & 64 & 41 & 64,06 \\
$\left(2^{\circ}\right.$ ano $)$ & Medicina & 64 & 38 & 59,37 \\
$\left(3^{\circ}\right.$ ano $)$ & Medicina & 66 & 64 & 96,96 \\
$\left(4^{\circ}\right.$ ano $)$ & Medicina & 60 & 45 & 75,00 \\
$\left(5^{\circ}\right.$ ano $)$ & Medicina & 65 & 61 & 93,84 \\
$\left(6^{\circ}\right.$ ano $)$ & Medicina & 65 & 30 & 46,15 \\
$\left(1^{\circ}\right.$ ano $)$ & Enfermagem & 60 & 52 & 86,66 \\
$\left(2^{\circ}\right.$ ano $)$ & Enfermagem & 62 & 0 & 0 \\
$\left(3^{\circ}\right.$ ano $)$ & Enfermagem & 63 & 44 & 69,84 \\
$\left(4^{\circ}\right.$ ano $)$ & Enfermagem & 57 & 0 & 0 \\
Total & & 627 & 375 & \\
\hline
\end{tabular}

Fonte: elaboração própria. 
Do total de alunos pesquisados, $54,3 \%$ declararam ser alérgicos; $83,7 \%$ destes alunos sabiam o agente desencadeante. Destes, 20\% têm alergia a algum tipo de medicamento. A maioria dos alunos declarou conhecer as possíveis reações vacinais $(59,7 \%)$, e $66,9 \%$ dos alunos não têm medo dessas possíveis reações.

Ainda indagamos se utilizam algum dos serviços de apoio ao aluno, prestados pela IES, e $19,5 \%$ informaram utilizar principalmente o Centro de Apoio Social ao Aluno (CASA).

Durante o período da pesquisa, a entrega da carteira vacinal foi sempre espontânea. Os alunos foram lembrados pelo menos três vezes no período: de avisos escritos a pedidos da pesquisadora em salas de aula.

Aparentemente, houve interesse em apresentar a carteira vacinal (oralmente durante a aplicação de questionários, em todas as turmas), uma vez que isso possibilitaria a atualização da carteira vacinal. Dos 627 alunos, apenas 69 apresentaram a carteira vacinal $(11,0 \%)$. Daqueles que apresentaram a carteira vacinal, $72,5 \%$ eram do gênero feminino. Não foi possível indicar a origem (curso) dos alunos, uma vez que não foi anotada em xerox.

Foi considerada a análise da carteira vacinal em relação às vacinas dupla adulto, dupla ou tríplice viral, febre amarela, influenza sazonal, hepatite B e varicela para a apresentação dos resultados.

Das carteiras vacinais apresentadas, 79,9\% estavam com a vacina dupla adulto em dia; $85,5 \%$ tinham pelo menos uma dose da vacina dupla ou tríplice viral; $62,3 \%$ tinham vacinação contra febre amarela; e 73,9\% apresentaram vacinação completa contra hepatite B (três doses). Já no caso da vacina contra gripe, apenas 2,9\% foram vacinados; $4,3 \%$ foram vacinados contra varicela; $5,8 \%$ apresentaram vacinação registrada contra hepatite A.

Não houve diferença estatisticamente significativa ( $p$ valor $>0,05$ ) na comparação de frequências de cada uma das vacinas (dupla adulto, tríplice ou dupla viral, febre amarela, gripe e hepatite B) em relação ao gênero.

Nenhuma das 69 carteiras vacinais estava de acordo com as vacinas sugeridas como obrigatórias aos alunos da graduação, assim como o são para os profissionais de saúde (Tabela 2).
Tabela 2. Vacinas preconizadas ao profissional de saúde distribuídas por gênero, anotadas em carteira vacinal, aos alunos da graduação da Famerp, de $1^{\circ}$ de agosto de 2006 a 31 de julho de 2007.

\begin{tabular}{lcc}
\hline Vacina & $\begin{array}{c}\text { Gênero feminino } \\
\text { (freq) } \mathbf{n}=\mathbf{5 0}\end{array}$ & $\begin{array}{c}\text { Gênero masculino } \\
\text { (freq) } \mathbf{n}=\mathbf{1 9}\end{array}$ \\
\hline Dupla adulto & 80,0 & 78,9 \\
Tríplice ou & 88,0 & 78,9 \\
dupla viral & & \\
Febre amarela & 64,0 & 57,9 \\
Gripe & 2,0 & 5,3 \\
Hepatite B & 78,0 & 63,2 \\
Varicela & 4,0 & 5,3 \\
\hline
\end{tabular}

Fonte: elaboração própria.

\section{Discussão}

A Famerp, com cursos de graduação em medicina e enfermagem, tem seus alunos inseridos na rede de saúde do município de São José do Rio Preto desde o primeiro ano de graduação ${ }^{7}$.

As doenças imunopreveníveis geralmente são associadas a prejuízos econômicos e sociais tanto para os casos - ou comunicantes de um caso quanto para as instituições de saúde e educação que, frequentemente, têm que enfrentar surtos e os transtornos decorrentes de afastamentos prolongados de profissionais, provocando inquietação para as gestantes e a necessidade de se manter as crianças acometidas afastadas, o que impossibilita seus responsáveis de trabalhar ${ }^{10}$.

A dificuldade de agendamento de aplicação de questionário levou as pesquisadoras a aumentar as oportunidades de relembrar cada turma da necessidade de fornecimento da carteira vacinal para xerografia.

Não foi medido se a carteira vacinal foi esquecida ou não encontrada (perdida) apenas com a resposta à solicitação feita. A baixa resposta à proposição inicial de levantamento do estado vacinal dos alunos dos dois cursos foi hipótese inicial considerada no delineamento desta pesquisa. A abordagem do problema reforça a necessidade de normatização e ampliação de suporte e orientação sob responsabilidade educacional da IES. Não há legislação a respeito encontrada pelas pesquisadoras.

Algumas IES têm um programa de saúde focado no aluno, porém sem regulamentação específica, fragilizando a manutenção da rotina ${ }^{7,11}$. O risco biológico existe, e a classe discente deve ter a comprovação de seu estado imune e receber 
imunobiológicos necessários regularmente no início dos cursos.

$\mathrm{Na}$ Famerp, todas as vacinas citadas (dupla adulto, tríplice ou dupla viral, febre amarela, gripe e hepatite B) estão disponíveis na Sala de Imunização, localizada no Ambulatório de Pediatria do Hospital de Base de São José do Rio Preto. Todos os trabalhadores da saúde da IES e do Hospital de Base/Hospital Universitário têm as vacinas à disposição, são agendados e imunizados conforme legislação vigente (NR-32) ${ }^{8}$.

Após negociação de docentes do Departamento de Epidemiologia e Saúde Coletiva da Famerp com a Secretaria Municipal de Saúde e Higiene, há fornecimento e disponibilidade dos imunobiológicos também para a classe discente da instituição.

A procura é pequena e normalmente ocorre por alunos do quarto ano da graduação de medicina durante o estágio prático em Saúde Coletiva, com abordagem prática do conteúdo imunização, conforme relato oral da enfermeira responsável pela Sala de Vacinas do Ambulatório de Pediatria do Hospital de Base ${ }^{12}$. Os alunos da enfermagem procuram por vacinas no período inicial de estágios, segundo relato da coordenação de curso, não havendo uma rotina própria no curso de enfermagem da Famerp ${ }^{13}$.

Em 2004, em ação de investigação epidemiológica e tomada de medidas de controle adequadas à varicela, houve alerta à IES, com vacinação de suscetíveis - inclusive os alunos da medicina e enfermagem que desenvolviam atividade intrahospitalar. Os dados desta vacinação de bloqueio não podem ser utilizados para comparação com as carteiras em razão da baixa resposta na entrega de carteiras vacinais obtida nesta pesquisa.

A maior proporção discente que respondeu ao questionário $(65,5 \%)$ em relação ao gênero não mostra diferenças estatisticamente significativas no curso de medicina, que tem $55,72 \%$ dos alunos matriculados do gênero feminino ( $\mathrm{p}$-valor $>0,05)$.

Na caracterização da população que respondeu ao questionário, verificamos que, mesmo sendo alunos de graduação de cursos de ciências da saúde, com maior acesso à informação e formação em imunização, isso não garante o compromisso da classe discente com a conservação e a preservação da carteira vacinal, bem como sua disponibilização ante a solicitação ${ }^{14}$.

Acesso à informação e orientação aparentemente há, ao verificarmos a escolaridade dos pais que, em grande proporção, têm curso superior completo ou ensino médio completo. Não é uma análise estatisticamente válida.
Não há diferença estatisticamente significativa na comparação das frequências de estudantes que moram com amigos, sozinhos ou com os pais ( $\mathrm{p}$-valor $>0,05$ ). Também não há evidências de diferença estatisticamente significativa entre os alunos que se declararam alérgicos e os não alérgicos. $O$ fator desencadeante da alergia foi bem definido ( $p$-valor $<0,05)$.

Não verificamos diferenças entre os que declararam conhecer as possíveis reações às vacinas e os que não declararam ou não conhecem ( -valor $>0,05)$, porém há declaração com diferença estatisticamente significativa entre os que não têm medo das possíveis reações e os que têm ( $\mathrm{p}$-valor > 0,05). O conhecimento declarado, portanto, fica discrepante com a resposta obtida para a solicitação da carteira vacinal e o atraso em vacinação em todas as cópias de carteiras vacinais entregues.

As vacinas da rotina vacinal do adulto apresentaram falhas importantes na cobertura vacinal (dupla adulto ou toxoide tetânico, febre amarela, hepatite $\mathrm{B}$ e dupla ou tríplice viral). Não houve diferença significativa na comparação de frequências entre gêneros.

\section{Conclusões}

Não houve resposta suficiente para avaliar o estado e o perfil vacinal da população de estudantes de medicina e enfermagem da Famerp de modo voluntário, mesmo com as várias oportunidades de apresentação de carteira vacinal e solicitação direta de docente da área de Epidemiologia e Saúde Coletiva.

O estudo do custo-benefício deve ser considerado para a realização de inquéritos sorológicos periódicos entre os profissionais de saúde em formação, considerando a disponibilidade de vacinas para os profissionais de saúde já formados na rede pública de saúde.

Todo aluno da área de saúde suscetível, grupo de risco à exposição a agentes biológicos, deve ser submetido à rotina vacinal completa do trabalhador em saúde, preferencialmente com a inclusão da vacina contra hepatite A.

Sem que haja a obrigatoriedade legal de controle do estado de saúde dos estudantes de medicina e enfermagem da Famerp - focos deste estudo - ou outra instituição de ensino superior (ou médio) da área das ciências da saúde, principalmente no que tange à vacinação, não haverá sucesso em iniciativas de cuidado à saúde voltadas ao estudante da graduação da instituição de ensino superior. 


\section{Colaboradores}

EMS Cabrera trabalhou na concepção do projeto, aplicação da pesquisa, análise estatística e redação final com revisão crítica; CES Merege, na redação do projeto, aplicação da pesquisa, digitação do banco de dados, acompanhamento da análise e redação final de texto.

\section{Agradecimentos}

À Faculdade de Medicina de São José do Rio Preto pela Bolsa de Auxílio à Pesquisa e pelo estágio de Iniciação Científica no período de $1^{\circ}$ de agosto de 2006 a 31 de julho de 2007.

\section{Referências}

1. São Paulo. Secretaria da Saúde. Coordenadoria dos Institutos de Pesquisa. Comissão Permanente de Assessoramento em Imunizações. Centro de Vigilância Epidemiológica Prof. Alexandre Vranjac. Norma Técnica do Programa de Imunização. 2a ed. São Paulo: Secretaria de Saúde de São Paulo; 2000.

2. Red Book. Relato do Comitê de Doenças Infecciosas. 26a ed. Rio de Janeiro: Editora de Publicações Científicas; 2003. (American Academy of Pediatrics, v. 1).

3. Farhat CK, Carvalho ES, Weckx LY, Carvalho HFR, Succi RCM organizadores. Imunizaçõe:s fundamentos e prática. 4a ed. São Paulo: Atheneu; 2000.

4. Anderson RM, May RM. Infectious diseases of humans: dynamics and control. Oxford: Oxford University Press; 1991.

5. Malta RF, Mishima SM, Almeida MCP, Pereira MJB. A utilização do inquérito domiciliar como instrumento de acompanhamento de ações de saúde em microáreas: analisando a situação vacinal de menores de um ano. Rev Latino-Am Enf 2002; 10(1):28-33.

6. Moraes JC, Barata RC, Ribeiro MCSA, Castro PC. Cobertura vacinal no primeiro ano de vida em quatro cidades do estado de São Paulo, Brasil. Pan Am J Public Health 2000; 8(5):332-341.

7. Brasil. Ministério da Saúde. Pró-saúde: programa nacional de reorientação da formação profissional em saúde. Brasília: Ministério da Saúde, Ministério da Educação; 2005. (Projetos, Programas e Relatórios, Série C).

8. Brasil. Ministério do Trabalho e Emprego. Norma Regulamentadora $n^{\circ} 32$ - NR 32 - Segurança e saúde no trabalho em serviços de saúde. Brasília: Ministério do Trabalho e Emprego; 2005.

9. Instituto Brasileiro de Geografia e Estatística (IBGE). Dados geográficos e populacionais de São José do Rio Preto, 2001. São Paulo: IBGE; 2001. (mimeo).

10. Gonçalves EL, Salles GP, Quaglia SR. Situação vacinal da população discente da Universidade de São Paulo. Rev Saude Publica 1977; 11:70-81.

11. Cabrera EMS. Avaliação da estratégia vacinal em São Paulo com base em estudo de soroprevalência [tese] São Paulo: Faculdade de Medicina da Universidade de São Paulo; 2004.

12. Falcão MD. Freqüência de imunização de alunos da Famerp na sala de vacinas do Ambulatório do Hospital de Base [relato oral]. São José do Rio Preto, SP: Famerp; 2007.

13. Furlan MFM. Incentivo à imunização dos alunos de graduação da enfermagem da Famerp [relato oral]. São José do Rio Preto, SP: Famerp; 2007.

14. Santos SLV, Souza ACS, Tipple AFV, Souza JT. O papel das instituições de ensino superior na prevenção das doenças imunopreveníveis. Rev Elet Enf [periódico na Internet] 8(1):91-98. [acessado 2007 jul 21]. 2006. [cerca de 8p.]. Disponível em: http:/ /www.fen.ufg.br/revista/revista8_1/original_12.htm

Artigo apresentado em 25/08/2007

Aprovado em 17/07/2008

Versão final apresentada em 06/08/2008 